\title{
Entorhinal Cortex
}

National Cancer Institute

\section{Source}

National Cancer Institute. Entorhinal Cortex. NCI Thesaurus. Code C97338.

A brain region in the medial temporal lobe near the hippocampus. 